\title{
Three-dimensional thermal structure of subduction zones: effects of obliquity and curvature
}

\author{
A. K. Bengtson ${ }^{1, *}$ and P. E. van Keken ${ }^{1}$ \\ ${ }^{1}$ Department of Earth and Environmental Sciences, Ann Arbor, MI, USA \\ *now at: Department of Materials Science and Engineering, University of Wisconsin, Madison, WI, USA
}

Correspondence to: P. E. van Keken (keken@umich.edu)

Received: 28 June 2012 - Published in Solid Earth Discuss.: 19 July 2012

Revised: 4 October 2012 - Accepted: 5 October 2012 - Published: 22 November 2012

\begin{abstract}
Quantifying the precise thermal structure of subduction zones is essential for understanding the nature of metamorphic dehydration reactions, arc volcanism, and intermediate depth seismicity. High resolution twodimensional (2-D) models have shown that the rheology of the mantle wedge plays a critical role and establishes strong temperature gradients in the slab. The influence of threedimensional (3-D) subduction zone geometry on thermal structure is however not yet well characterized. A common assumption for 2-D models is that the cross-section is taken normal to the strike of the trench with a corresponding velocity reduction in the case of oblique subduction, rather than taken parallel to velocity. A comparison between a full 3D Cartesian model with oblique subduction and selected 2$\mathrm{D}$ cross-sections demonstrates that the trench-normal crosssection provides a better reproduction of the slab thermal structure than the velocity-parallel cross-section. An exception is found in the case of a strongly curved trench, such as in the Marianas, where strong 3-D flow in the mantle wedge is generated. In this case it is shown that the full 3-D model should be evaluated for an accurate prediction of the slab thermal structure. The models demonstrate that the use of a dynamic slab and wedge, separated by a kinematic boundary, yields good results for describing slab velocities in 3-D.
\end{abstract}

\section{Introduction}

Predictions of temperature in the subducting slab have been of interest since the early days of plate tectonics. The advection of low temperature conditions from the surface into the Earth's interior is important for understanding the mech- anisms of intermediate-depth and deep seismicity (Kirby et al., 1996; Hacker et al., 2003; Abers et al., 2006; Faccenda et al., 2012; Barcheck et al., 2012; van Keken et al., 2012), the metamorphic dehydration of the slab (Connolly, 1997), the release of fluids to the overlying slab (Cagnioncle et al., 2007; Wada et al., 2012), and the subduction of volatiles to the Earth's deep interior (Hirschmann, 2006; van Keken et al., 2011; Parai and Mukhopadhyay, 2012). Thermal models have also become increasingly important in the interpretation of arc geochemistry (e.g., Kimura et al., 2009, 2010; Turner et al., 2012).

One approach to model the thermal structure of the downgoing lithosphere is to kinematically project the slab into the mantle. While this is a clear simplification from models that treat the slab as a dynamic entity (e.g., Zhong and Gurnis, 1995; Kincaid and Sacks, 1997; van Hunen et al., 2002), this approach allows for the use of observed slab geometries (e.g., England et al., 2004; Syracuse and Abers, 2006; Hayes et al., 2012) and can take into account geodetic and paleomagnetic data to accurately prescribe convergence velocities and plate ages (e.g., DeMets et al., 1994; Müller et al., 2008). Early thermal models were based on a simple advection-diffusion scheme for the slab with parameterized wedge coupling (Toksöz et al., 1971). The dynamics of subduction zones is complicated by the structure of the mantle wedge, which is the convecting portion of the mantle above the slab and below the overriding lithosphere (van Keken, 2003; Wiens et al., 2008). Entrainment of the mantle wedge by the subducting slab sets up a cornerflow in the wedge which leads to very strong thermal boundary layers. Early models that took into account the dynamics of the wedge often used a simplified isoviscous rheology for the wedge (e.g., 

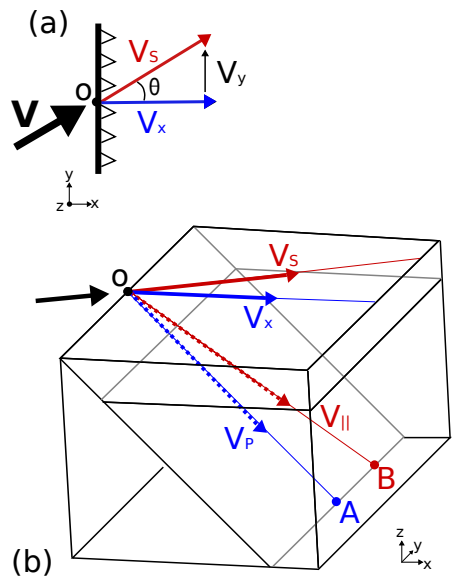

(c)
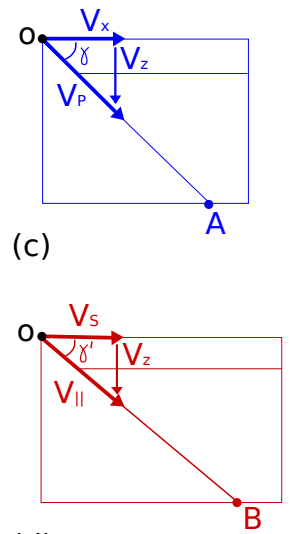

(d)

Fig. 1. Oblique subduction model with straight trench. (a) Map view of incoming plate velocity. (b) Full 3-D model. (c) 2-D crosssection of trench perpendicular flow. (d) 2-D cross-section parallel to incoming plate velocity angle. The origin, $O$, and points $A$ and $B$ connect models (a-d). $V_{S}$ is the velocity along the incoming plate direction at angle $\theta$ to the trench. $V_{X}$ is the velocity perpendicular to the trench. $V_{Z}$ is the velocity in the z-direction (into the Earth). $V_{\|}$is the component of the velocity parallel to the incoming plate direction on the slab surface. $V_{P}$ is the component of the trench normal component of the velocity on the slab surface (trench normal). The trench dips from the surface at an angle $\gamma$. The slab dip parallel to the incoming plate velocity $\left(\gamma^{\prime}\right)$ is less than the dip perpendicular to the trench $(\gamma)$.

Davies and Stevenson, 1992; Peacock and Wang, 1999), with only few exceptions (Furukawa and Uyeda, 1989). Only more recently the more appropriate temperature- and stressdependent properties of the wedge have been consistently taken into account, which causes a significant increase in slab surface temperature compared to isoviscous models (van Keken et al., 2001; Kelemen et al., 2003; Conder et al., 2005). A detailed comparison between independent finite-difference and finite-element methods showed that the results for thermal structure agreed well, but only if fairly high resolution (a few kilometer grid spacing or less) is used (van Keken et al., 2008).

We have some confidence that the recent generation of this type of kinematic-dynamic model for subduction zones leads to reasonable and well-resolved thermal structures. Aside from the benchmark comparison (van Keken et al., 2008), the temperature of the slab below a number of volcanic arcs predicted in a global suite of subduction models (Syracuse et al., 2008) agrees remarkably well with fully independent geochemical estimates for slab surface temperatures (Plank et al., 2009; Skora and Blundy, 2010; Cooper et al., 2012). In many models, 2-D cross-sections are still commonly used. This is partly out of the implied understanding (or hope) that the thermal structure is dominated by movement in the convergence direction, with little variations along strike, partly for geometrical convenience and computational efficiency.
This raises some important questions. Can we successfully use 2-D models to estimate the thermal structure of 3-D subduction zones? What is the appropriate choice of crosssection through a subduction zone in the case of oblique convergence, or in the case of strong trench curvature?

When one attempts to model specific subduction zones, an important choice of location of the cross-section has to be made. While this choice is clear in the case of normal convergence, it is not in the case of oblique convergence. Consider the simple 3-D geometry in Fig. 1 where we assume the slab is a straight plane dipping under angle $\gamma$. The convergence velocity $V_{S}$ has a horizontal angle $\theta$ with the trench normal. Two cross-section choices seem obvious: (1) the crosssection parallel to convergence velocity (in the direction of $V_{S}$, which causes a shallowing of the subducting plane to $\gamma^{\prime}$ ) and (2) the cross-section normal to the trench (using the real dip $\gamma$ but a reduced convergence velocity $V_{\mathrm{p}}$ ). To date it has not been demonstrated which of these two options is the most appropriate. The choice of cross-section is even more complicated in the case of strongly curved subduction zones (Fig. 2), such as the Marianas and Antilles subduction zones. Two-dimensional models for these geometries fail to account for 3-D flow in the wedge. Seismological observations of seismic anisotropy that show a dominance of trenchparallel shear-wave splitting in subduction zones, strongly suggest that 3-D flow, with a strong along-arc component, may be significant (for recent reviews see Long and Silver, 2008; Long and Becker, 2010). Three-dimensional flow is also indicated by geochemistry of arc lavas (e.g., Hoernle et al., 2008) and has been supported by dynamical models (Honda and Yoshida, 2005; Kneller and van Keken, 2007, 2008; Jadamec and Billen, 2010, 2012; Stadler et al., 2010; Alisic et al., 2010).

The goal of this paper is two-fold. We wish to investigate which 2-D geometry is appropriate in the case of oblique convergence in subduction zones with little along-strike variation in geometry (Fig. 1) and whether we can use this approach in the case of strongly curved arcs (Fig. 2). We will show that the strike-normal choice (Fig. 1c) recovers the 3-D thermal structure accurately and that the convergenceparallel (Fig. 1d) choice does not. Neither approach is well suited for the case of oblique convergence in strongly curved arcs, except under special circumstances.

\section{Modeling approach}

We use high-resolution 3-D finite element models to predict the thermal structure of subduction zones using the simplified geometries of Fig. 3a and b. We compare these predictions with selected 2-D cross-sections. The models closely follow the description of the benchmark (van Keken et al., 2008). One important modification is that instead of prescribing the slab as a kinematic entity, we now prescribe the velocity as an internal boundary condition along the slab 


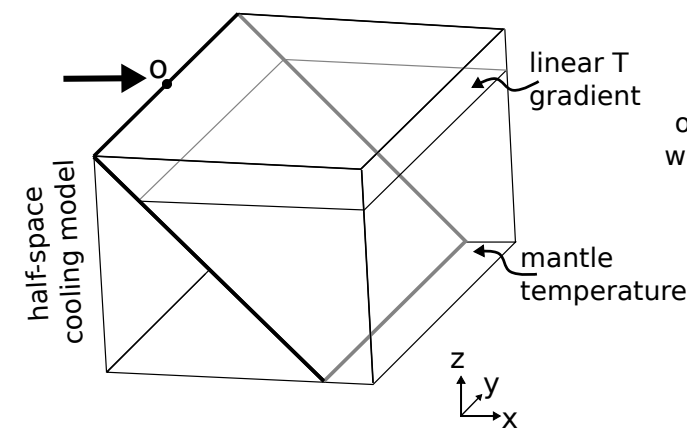

(a) temperature boundary conditions for 3D geometries

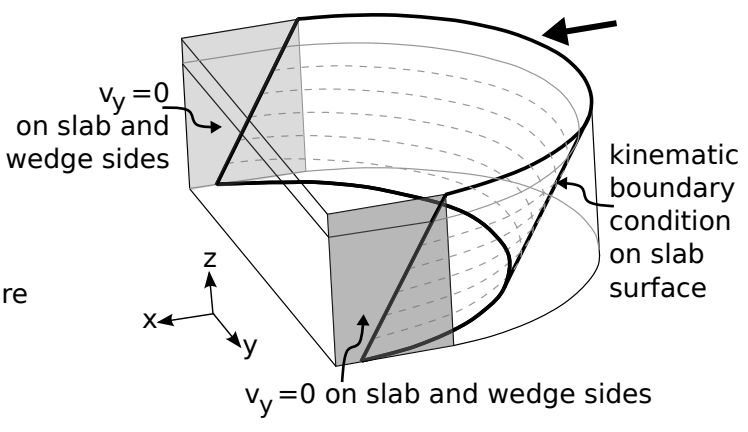

(b) velocity boundary conditions for curved trench

Fig. 2. (a) Temperature and (b) velocity boundary conditions for three-dimensional geometries. The y-component of velocity $\left(V_{y}\right)$ is forced to zero in (b).

surface. The mantle wedge, slab, and underlying asthenosphere are assumed to be infinite Prandtl, incompressible fluids that are entrained by the kinematic boundary condition. The top $50 \mathrm{~km}$ of the mantle wedge is assumed to be rigid, which mimics the crust and shallow lithosphere of the overriding plate. For the mantle portions in the wedge and slab we solve the Stokes equations, which represent the conservation of mass and momentum:

$\nabla \cdot \bar{u}=0$

and

$0=-\nabla p+\nabla \cdot \tau$,

where $u$ is the velocity, $p$ is the pressure, $T$ is the temperature, and the deviatoric stress, $\tau$, is the product of viscosity and strain rate:

$\tau=\eta \dot{\varepsilon}=\eta\left(\nabla \bar{u}+\nabla \bar{u}^{T}\right)$.

In most cases we use the Frank-Kamnetski simplification of the full Arrhenius temperature-dependence of viscosity $\eta$ :

$\eta(T)=\exp \left[-\ln (1000) T / T_{\text {mantle }}\right]$

where $T_{\text {mantle }}$ is the mantle potential temperature. We solve the steady-state heat advection-diffusion equation on the entire domain:

$\bar{u} \cdot \nabla T=\nabla^{2} T+H$.

For simplicity we ignore shear heating, thermal buoyancy in the mantle wedge and internal heating $\mathrm{H}$, except for in the crust of the overriding plate (following van Keken et al., 2008). This internal heating mode has little effect on the slab thermal structure but allows us to directly compare our results to those of the benchmark. The boundary conditions are similar to those of the subduction zone benchmark (van Keken et al., 2008) and are indicated in Fig. 2. In the case of oblique subduction in the straight-slab model (Fig. 2a), we use periodic boundary conditions on the side boundaries to mimic an infinitely-long subduction system. For the boundary condition of the incoming plate, we use a half-space cooling profile appropriate for the thermal structure of $50 \mathrm{Ma}$ oceanic lithosphere, except for the model in Fig. 2b where we assume $100 \mathrm{Ma}$ (which is more appropriate for the incoming structure of the lithosphere in the Marianas).

We assume for all models a convergence speed of $5 \mathrm{~cm} / \mathrm{yr}$ and a mantle potential temperature of $1300^{\circ} \mathrm{C}$. All constant thermodynamic parameters and non-dimensionalization follow van Keken (2008). The governing equations are spatially discretized using the Galerkin method employed by the Sepran finite element method (Cuvelier et al., 1986; http: //ta.twi.tudelft.n1/NW/sepran). We use grid refinement in the boundary layers with $0.5 \mathrm{~km}$ spacing between nodal points as highest resolution. Far away from the boundary layers, the resolution is generally about 10 to $20 \mathrm{~km}$. We use linear tetrahedral (3-D) and triangular (2-D) elements. For the Stokes equations we use the Taylor-Hood elements that allow for solution in primitive variables and iterative methods. We use the Cubit (http://cubit.sandia.gov) mesh generator for the 3D mesh generation and Paraview (www.paraview.org) for visualization of the 3-D structures. The 2-D cross-sections are generated with the Sepran mesh generators, but use similar grid refinements as in the 3-D case. For the heat equation we use streamline upwinding. The resulting matrix-vector systems are solved iteratively using the BiCGstab method (van der Vorst, 1992). We use Picard iteration to resolve the nonlinearity between the Stokes and heat equations.

\section{Results}

\subsection{Subduction zone benchmark in 3-D}

To validate the three-dimensional modeling, we use the geometry in Fig. 1a with normal convergence. The resulting 

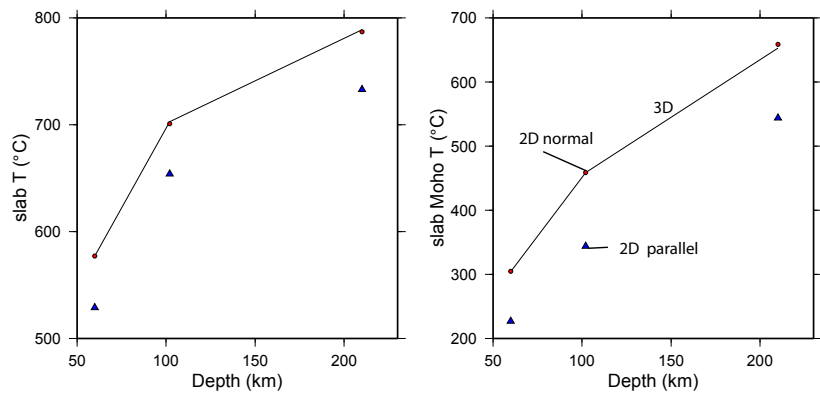

Fig. 3. Predicted slab surface (left) and slab Moho (right) temperatures at selected depths for the straight-slab model (Fig. 2a) and oblique convergence $\left(\theta=60^{\circ}\right)$. The straight line indicates the 3-D results. The method that chooses the $2-\mathrm{D}$ cross-section normal to strike (red circles, "2-D normal") matches the 3-D model to a high precision, whereas the model that has the cross-section parallel to convergence velocity (blue triangles, "2-D parallel") significantly underestimates the temperature distribution.

solution does not change in the along-strike direction, and we can directly compare the temperature predictions with the benchmark cases (van Keken et al., 2008). We solve the benchmark cases 1c (isoviscous wedge rheology with natural boundary conditions) and $2 \mathrm{a}$ (diffusion creep rheology in the wedge and natural boundary conditions). We use grid refinement near the cornerpoint with smallest grid spacing ranging from $2 \mathrm{~km}$ to $0.5 \mathrm{~km}$. The coarsest grid resolution is $20 \mathrm{~km}$. Maybe not surprisingly, the resulting temperature structure is nearly identical to that found in our 2-D results. The main results (and convergence trend with increasing mesh resolution) follow that in van Keken et al. (2008; their Fig. 3). For example, in the highest resolution model we find a temperature at $60 \mathrm{~km}$ depth along the slab surface of $387^{\circ} \mathrm{C}$ (compared to the benchmark's "best estimate" of $388^{\circ} \mathrm{C}$ in 2-D) for case $1 \mathrm{c}$. For case $2 \mathrm{a}$ this value is $578^{\circ} \mathrm{C}$ in $3-\mathrm{D}$ (compared to the "best estimate" of $583^{\circ} \mathrm{C}$ in 2-D). We ascribe the minor differences to the fact that the 2-D meshes are better balanced (and less coarse away from the boundary layers) and that we could use finer spacing in the 2-D benchmark.

We compared our new approach of prescribing velocity along the slab surface (and solving the Stokes equations in the slab) with the benchmark method of prescribing velocity throughout the slab. We found minor differences in the isoviscous case, but no difference (to within a degree) with temperature-dependent viscosity. Clearly, the higher viscosity of the slab renders it as a nearly kinematic entity, causing the velocity to be similar to that of the kinematic case. The use of an internal boundary is useful in 3-D, where (except for the simple case of the straight slab) it becomes difficult to define the velocity inside the slab. In 2-D this can be achieved by finding the point on the slab surface that is closest and taking the same velocity as in that slab point. This becomes significantly more difficult for a general 3-D slab surface. The use of a dynamic slab also resolves an important weakness of the kinematic-slab models: with a kinematic prescription the conservation of mass and momentum are not satisfied, except in the simplest cases. With the new approach using a dynamic slab, this weakness is removed.

\subsection{Comparison 1: oblique subduction with straight trench}

The first new model comparison addresses the question whether 2-D cross-sections should be taken parallel to convergence (case "2-D parallel"; see red arrows in Fig. 1a, b and geometry in Fig. 1d) or normal to structure with reduced velocity (case "2-D normal"; Fig. 1c). We use the rectangular box of Fig. 1b, with dimensions of $270 \mathrm{~km}$ in $x, 100 \mathrm{~km}$ in $y$, and $250 \mathrm{~km}$ in $z$ (depth). The trench strike is in $y$ and the trench-normal velocity points to $x$. We use periodic boundary conditions on the planes with constant $y$ which allows for the short model dimension in $y$. The slab dip $\gamma=45^{\circ} . \theta$ is the angle between the convergence velocity and $x$. We varied $\theta$ between $0^{\circ}$ (normal) and $60^{\circ}$ (strongly oblique). In this case we solve the Stokes equations in the wedge only. The velocity in the slab has components

$$
\begin{aligned}
& V_{x}=v \cos \gamma \\
& V_{y}=v \tan \theta \cos \gamma . \\
& V_{z}=-v \sin \gamma
\end{aligned}
$$

This velocity field also forms the slab-side boundary condition for the wedge (with a $3 \mathrm{~km}$ long taper in the wedge tip as in van Keken et al., 2008). In this case we used the viscosity function (4). In the "2-D normal" geometry, the dip of the slab remains the same, but the effective velocity in the slab surface should be reduced. In the "2-D parallel" geometry, the velocity is unchanged, but the slab shallows. Fig. 3 shows the comparison between these 2-D approaches and the full 3-D model for the largest obliquity by plotting the temperature in the slab surface (left) and that in the slab Moho (7 km below the slab surface; right) at a number of depths. It is clear that "2-D normal" case, which is the common choice of taking the cross-section normal to strike (e.g., Syracuse et al., 2010), is indeed appropriate. We see only very small differences (up to $2{ }^{\circ} \mathrm{C}$ ), whereas the "2-D parallel" results significantly underpredict the temperature with a largest difference of more than $100^{\circ} \mathrm{C}$. This is pronounced throughout the top of the slab and not just at the interface itself. For smaller $\theta$ the error in "2-D parallel" becomes smaller; for all cases considered, the "2-D normal" results are, for practical purposes, identical to the 3-D case. The effective shallowing of the slab in "2-D parallel" is the main reason for the cooler predictions: the entrained flow cannot move into the wedge corner as efficiently compared to the model with the larger dip and the boundary layers are effectively broadened. 

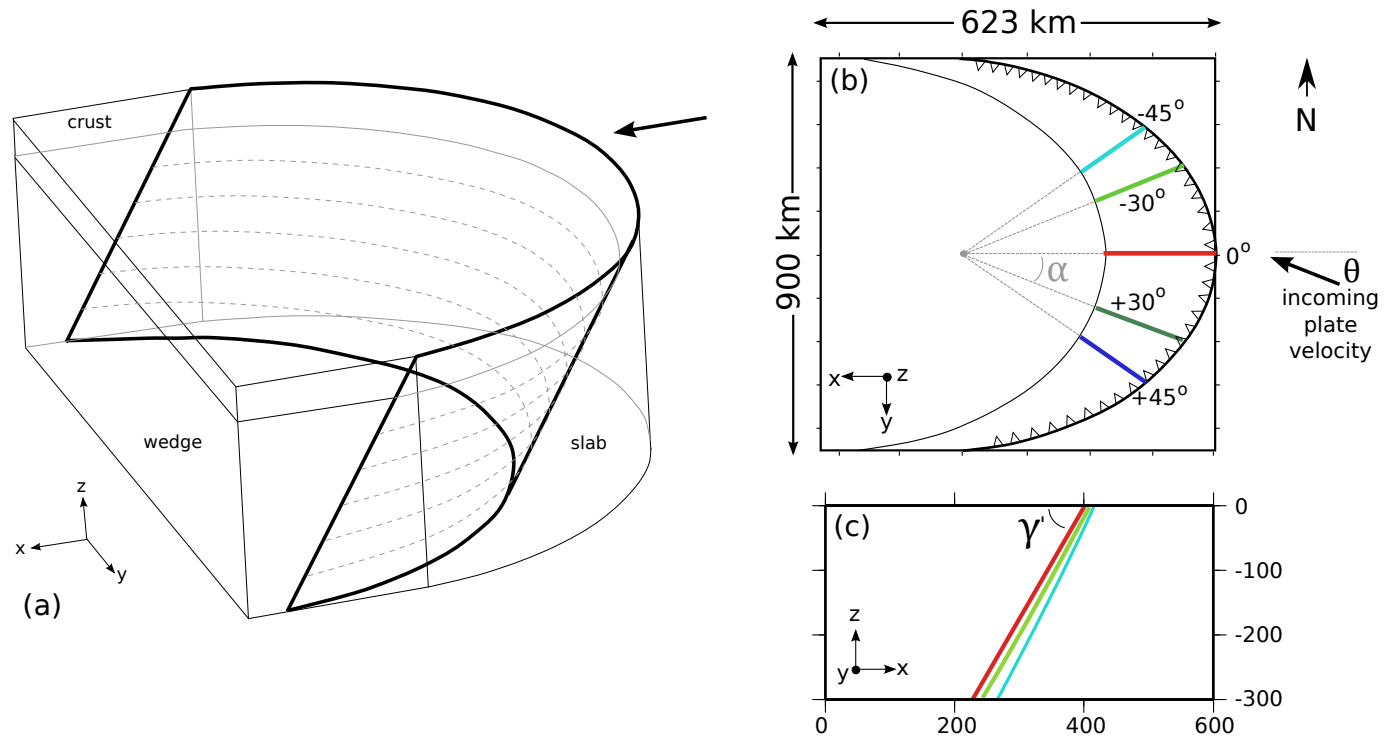

Fig. 4. Oblique subduction model with a curved trench dipping at angle $\gamma$. Incoming plate velocity is oblique at angle $\theta$. Cross-sections are studied along $\pm 0^{\circ}, 30^{\circ}$, and $45^{\circ}$. (a) Map view of slab surface. (b) Velocity is prescribed only on the surface of the slab; the mantle wedge and slab are dynamic. (c) Slab dip $\left(\gamma^{\prime}\right)$ depends on $\alpha$. Each 2-D cross-section extracts the appropriate $\gamma^{\prime}$ for $\alpha$.

\subsection{Comparison 2: curved trench}

In the second new comparison, we investigate the consequences of 3-D flow in models with a curved trench and a normal or obliquely subducting plate (Fig. 4a). This is relevant for models for a number of arcs, including the Marianas, Alaska-Aleutian, Antilles and Scotia subduction systems. For this comparison we use the geometry of a subduction zone with a curved trench from Kneller and van Keken (2007) which has some likeness to the Marianas subduction zone. The model parameters follow that of Comparison 1, with the exceptions that the slab and mantle wedge are now both dynamic and that the normal velocity on the sides with constant $y$ (indicated in grey in Fig. 2b) are set to zero, effectively causing symmetry boundary conditions here. We consider again an obliquity $\theta$ of the convergence velocity. We will consider a number of cross-sections that all start in the center of the arc and have an angle $\alpha$ with respect to the symmetry axis of the arc (Fig. 4b). This leads to minor variations in the apparent dip angle $\gamma^{\prime}$ (Fig. 4c). The choices for $\alpha\left(0^{\circ}\right.$, $\pm 30^{\circ}, \pm 45^{\circ}$ ) are indicated in Fig. $4 \mathrm{~b}$. We consider convergence that is parallel to the symmetry axis $\left(\theta=0^{\circ}\right)$, for which the results to the north and south of the symmetry axis will logically be similar, and an oblique case $\left(\theta=30^{\circ}\right)$ which is approximately the same as that in the Marianas subduction zone.

The change in obliquity has a significant influence on the mantle wedge flow (Fig. 5). For $\theta=0^{\circ}$ we see a flow pattern with mildly 3 -D characteristics. The 3-D nature is more subdued compared to that observed in Kneller and van Keken (2007), presumably because we use a simplified Newtonian viscosity law here instead of the full non-linear olivine creep law use in Kneller and van Keken (2007). This comparison may indicate that non-Newtonian effects have a significant effect on wedge flow patterns, as suggested by Jadamec and Billen (2010, 2012). In the case of oblique convergence $\left(\theta=30^{\circ}\right)$, we see the wedge flow shows a dramatic asymmetry in speed (significantly higher in the south) and direction. The particle paths show strong toroidal behavior (Fig. 5b). The effect on the slab temperature paths at the slab surface and the slab Moho is shown in Fig. 6. Even in the symmetric case, the slab temperature paths differ by several tens of degrees. This is due to the combined effects of the 3-D flow in the wedge and the transport of slab material through the plane of the cross-section. As $\theta$ increases, differences in the slab temperature paths become more pronounced and asymmetric in $\alpha$.

We compare this 3-D model to 2-D models based on the five cross-sections shown in Fig. 4b. We take here the "2-D normal" approach of Sect. 2.3. The temperature differences between 2-D and 3-D at the slab surface and the Moho at a depth of $150 \mathrm{~km}$ are shown in Fig. 7. For $\theta=0$, variations are significant and increase up to $60^{\circ} \mathrm{C}$ for the largest $\alpha$. In the oblique convergence case, the differences are significantly more pronounced in the northern section (negative $\alpha$ ). The 2D models significantly overpredict the temperature, in large part due to the low effective velocity (which is due to both the angle of the cross-section and the oblique convergence). In the 3-D case there is significant advection of slab material from outside of the plane, causing significantly lower temperatures. 


$\begin{array}{lllll}0 & 2 & 4 & 6 & 8\end{array}$

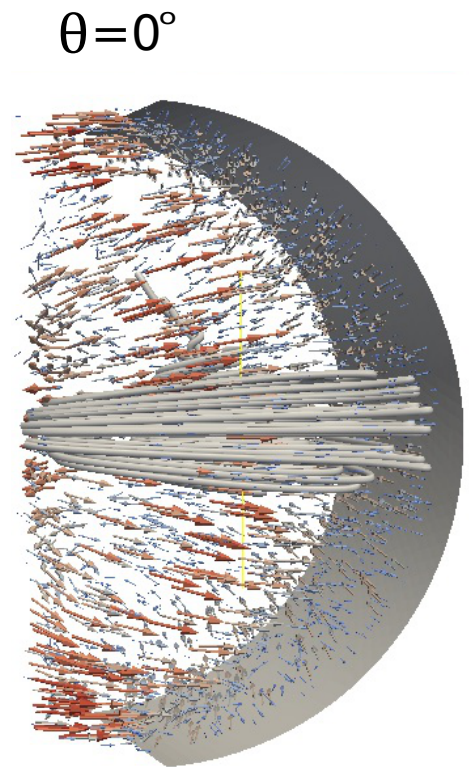

(a)

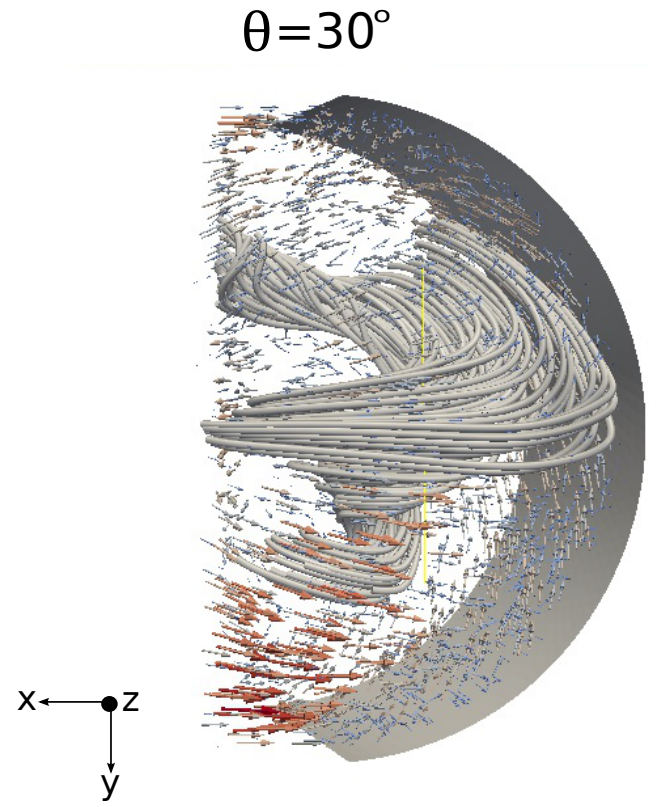

(b)

Fig. 5. Velocity in the mantle wedge for the curved trench with oblique subduction. Changing the incoming plate velocity $\theta$ from (a) $0^{\circ}$ to (b) $30^{\circ}$ drastically changes the flow pattern. The color scale reflects speed in $\mathrm{cm} \mathrm{yr}^{-1}$. Streamlines are seeded from a small volume at the right hand boundary.
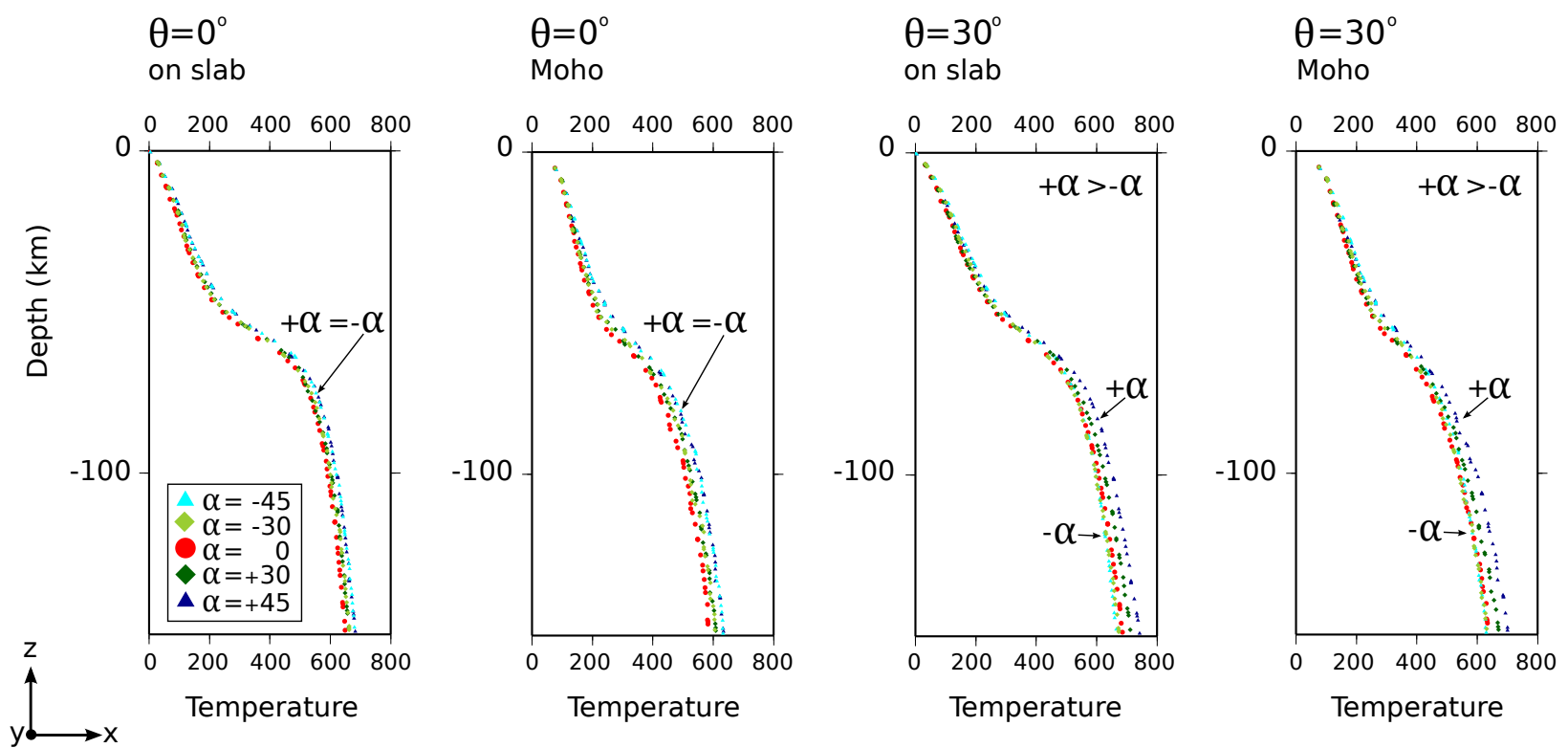

Fig. 6. Temperatures on the slab $(\mathbf{a}, \mathbf{c})$ and on the Moho $(\mathbf{b}, \mathbf{d})$ for the curved trench with oblique subduction. Temperatures along multiple cross-sections, $\alpha$ ( $\alpha$ is defined in Fig. 4), are plotted. (a) Incoming plate velocity $\theta=0^{\circ}$. (b) Incoming plate velocity $\theta=30^{\circ}$. 

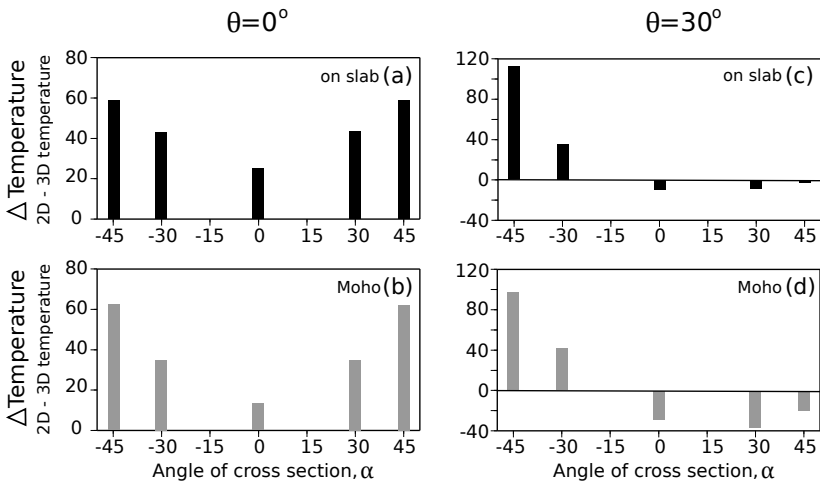

Fig. 7. Differences between the two-dimensional (2-D) and threedimensional (3-D) temperature solutions for curved trench at a depth of $150 \mathrm{~km}\left(\Delta T=T_{2-\mathrm{D}}-T_{3-\mathrm{D}}\right)$. Temperature differences are given for a slab velocity angle of $0^{\circ}(\mathbf{a}, \mathbf{b})$ and $30^{\circ}(\mathbf{c}, \mathbf{d})$. Temperature differences are plotted directly on the slab $(\mathbf{a}, \mathbf{c})$ and on the Moho $(\mathbf{b}, \mathbf{d})$. Note the difference in vertical axes between $\theta=0^{\circ}$ and $\theta=30^{\circ}$.

The choice of a good cross-section for 2-D models is clearly more difficult with a curved trench. Only in the case of cross-sections that run subparallel to the convergence direction $(\alpha \sim \theta)$ are the 2-D models reasonable. Twodimensional models cannot accurately predict the thermal structure when the cross-section is under a significant angle from the convergence direction.

\section{Discussion}

Thermal models of subduction zones, which are important in the understanding of their geophysical and geochemical structure and evolution, are still commonly based on 2-D modeling. We have investigated to which extent the 2-D approach is reasonable. Based on our first comparison we argue that the common approach of taking the cross-section normal to strike with reduced velocity is reasonable in the many arcs that have little along-strike variation. In arcs that show significant curvature (e.g., Marianas, Alaska-Aleutian), we predict that only the cross-sections that run subparallel to the flow may be applicable. Models that take cross-sections under a large angle to convergence direction (such as the Northern Marianas model in Syracuse et al., 2010) should be treated with caution. Similarly, subduction zones that have oblique convergence and variations in the thermal structure (e.g., due to age of the slab at the trench) or temporal variability in the input parameters (e.g., Lee and King, 2010) should ideally be studied with full 3-D geometry.

We have limited geochemical evidence that can provide direct tests of our suggestion that the slab surface temperature is more realistic in the 3-D model. The dominance of data is for the central arc, for which we predict only small temperature variations. For the Northern Marianas, where the difference between 2-D and 3-D model predictions are largest, we are only aware of one study. Tollstrup and Gill (2005) suggested from Hf isotope data that the slab surface should be above the wet sediment solidus, but less than 705$780{ }^{\circ} \mathrm{C}$. The $2-\mathrm{D}$ model predicts about $800^{\circ} \mathrm{C}$ below the arc, which is reduced to $720-740^{\circ} \mathrm{C}$ in the $3-\mathrm{D}$ model, which is in better agreement with the geochemical constraints. We have not studied the flow around a slab edge in detail. This is relevant in a number of subduction zones (including central Alaska and southern Cascades). Recent modeling has suggested that flow around slab edges may be significant (Kneller and van Keken, 2008; Jadamec and Billen, 2010, 2012). Of particular interest are the very high velocities predicted for non-Newtonian flow around slab edges (Jadamec and Billen, 2010, 2012). In this case one would expect a dramatic increase in slab surface temperatures, with significant changes in arc geochemistry. Future work on determining realistic models for subduction zone thermal structure needs to take these slab edge and rheological effects into account.

Aside from non-Newtonian effects, which we did not address in this study, these model comparisons should be extended with more realistic wedge descriptions, which include the roles of buoyancy and low viscosity (Billen and Gurnis, 2001) that may lead to additional 3-D flow patterns (e.g., Honda and Yoshida, 2005), dynamic erosion of the overriding plate (Currie and Hyndman, 2006; Arcay et al., 2007), mantle compressibility (Lee and King, 2009) and the effects of fluids and melt on wedge rheology (e.g., Hirth and Kohlstedt, 1996).

Acknowledgements. We appreciate discussions with Margarete Jadamec and Magali Billen regarding the dynamics of wedge flow around slab edges. Supported by the National Science Foundation grants EAR 0646757 and 0840448 and the Turner Postdoctoral Fellowship at the University of Michigan. We thank Ikuko Wada and an anonymous reviewer for constructive remarks that helped improve the manuscript, and Francesca Funiciello for editorial comments. We think Jim Gill for pointing out geochemical constraints on the slab surface temperature in the Northern Marianas.

Special Issue: "Subduction zones"

Edited by: S. Buiter, F. Funiciello, and J. van Hunen

\section{References}

Abers, G. A., van Keken, P. E., Kneller, E. A., Ferris, A., and Stachnik, J. C.: The thermal structure of subduction zones constrained by seismic imaging: implications for slab dehydration and wedge flow, Earth Planet. Sci. Lett., 241, 387-397, 2006.

Alisic, L., Gurnis, M., Stadler, C., Burstedde, C., Wilcox, L. D., and Ghattas, O.: Slab stress and strain rate as constraints on global mantle flow, Geophys. Res. Lett., 37, L22308, doi:10.1029/2010GL045312, 2010.

Arcay, D., Tric, E., and Doin, M.-P.: Slab surface temperature in subduction zones: influence of the interplate decoupling depth and upper plate thinning processes, Earth Planet. Sci. Lett., 255, 324-338, 2007. 
Barcheck, G. C., Wiens, D. A., van Keken, P. E., and Hacker, B. A.: The relationship of intermediate- and deep-focus seismicity to hydration and dehydration of subducting slabs, Earth Planet. Sci., 349-350, 153-160, 2012.

Billen, M. I. and Gurnis, M.: A low viscosity wedge in subduction zones, Earth Planet. Sci. Lett., 193, 227-236, 2001.

Cagnioncle, A.-M., Parmentier, E. M., and Elkins-Tanton, L. T.: Effect of solid flow above a subducting slab on water distribution and melting at convergent plate boundaries, J. Geophys. Res., 112, B09402, doi:10.1029/2007JB004934, 2007.

Conder, J. A.: A case for hot slab surface temperatures in numerical viscous flow models in subduction zones with an improved fault zone parameterization, Phys. Earth Planet. Int., 149, 155-164, 2005.

Connolly, J. A. D.: Devolatilization-generated fluid pressure and deformation-propagated fluid flow during prograde region metamorphism, J. Geophys. Res., 102, 18149-18173, 1997.

Cooper, L. B., Ruscitto, D. M., Plank, T., Wallace, P. J., Syracuse, E. M., and Manning, C. E.: Global variations in $\mathrm{H}_{2} \mathrm{O} / \mathrm{Ce}$ : 1. Slab surface temperatures beneath volcanic arcs, Geochem. Geophys. Geosyst., 13, Q03024, doi:10.1029/2011GC003902, 2012.

Currie, C. A. and Hyndman, R. D.: The thermal structure of subduction zone back arcs, J. Geophys. Res., 111, B08404, doi:10.1029/2005JB004024, 2006.

Cuvelier, C., Segal, A., and van Steenhoven, A. A.: Finite element models and the Navier-Stokes equations, D. Reidel, Dordrecht, The Netherlands, 1986.

Davies, J. H., and Stevenson, D. J.: Physical model of source region of subduction zone volcanics, J. Geophys. Res., 97, 2037-2070, 1992.

DeMets, C., Gordon, R. G., Argus, D. F., and Stein, S.: Effect of recent revisions to the geomagnetic reversal time-scale on estimates of current plate motions, Geophys. Res. Lett., 21, 21912194, 1994.

England, P., Engdahl, R., and Thatcher, W.: Systematic variation in the depths of slabs beneath arc volcanoes, Geophys. J. Int., 156, 377-408, 2004.

Faccenda, M., Gerya, T. V., Menktelow, N. S., and Moresi, L.: Fluid flow during slab unbending and dehydration: implications for intermediate-depth seismicity, slab weakening and deep water recycling, Geochem. Geophys. Geosyst., 13, Q01010, doi:10.1029/2011GC003860, 2012.

Furukawa, Y. and Uyeda, S., Thermal state under the Tohoko arc with consideration of crustal heat generation, Tectonophysics, 164, 175-187, 1989.

Hacker, B. R., Peacock, S. M., Abers, G. A., and Holloway, S. D.: Subduction Factory 2: Are intermediate depth earthquakes in subducting slabs linked to metamorphic dehydration reactions? J. Geophys. Res., 108, art. no. 2030, 2003.

Hayes, G. P., Wald, D. J., and Johnson, R. L., Slab 1.0: A threedimensional model of global subduction zone geometries, J. Geophys. Res., 117, B01302, doi:10.1029/2011JB008524, 2012.

Hirschmann, M. M.: Water, melting and the deep Earth $\mathrm{H}_{2} \mathrm{O}$ cycle, Ann. Rev. Earth Planet. Sci., 34, 629-653, 2006.

Hirth, G. and Kohlstedt, D.: Water in the oceanic upper mantle: implications for rheology, melt extraction, and the evolution of the lithosphere, Earth Planet. Sci. Lett., 144, 93-108, 1996.

Honda, S. and Yoshida, T.: Effects of oblique subduction on the 3-D pattern of small-scale convection within the mantle wedge,
Geophys. Res. Lett., 32, L13307, doi:10.1029/2005GL023106, 2005.

Jadamec, M. A. and Billen: M. I., Reconciling surface plate motions with rapid three-dimensional mantle flow around a slab edge, $\mathrm{Na}$ ture, 465, 338-341, 2010.

Jadamec, M. A. and Billen, M. I.: The role of rheology and slab shape on rapid mantle flow: three-dimensional numerical models of the Alaska slab edge, J. Geophys. Res., 117, B02304, 2012.

Kelemen, P. B., Parmentier E. M., Rilling, J., Mehl, L., and Hacker, B. R.: Thermal convection in the mantle wedge beneath subduction-related magmatic arcs, in: The Subduction Factory, edited by Eiler, J., American Geophysical Union Monograph 138, 293-311, American Geophysical Union, Washington, D.C., 2003.

Kimura, J. I., Hacker B. R., van Keken, P. E., Kawabata, H., Yoshida, T., and Stern, R. J.: Arc Basalt Simulator (ABS) ver. 2, a simulation for slab dehydration and fluid-fluxed mantle melting for arc basalts: modeling scheme and application, Geochem. Geophys. Geosyst., 10, Q09004, doi:10.1029/2008GC002217, 2009.

Kimura, J. I., Kent, A. J. R., Rowe, M. C., Katakuse, M., Nakano, F., Hacker, B. R., van Keken, P. E., and Stern, R. J.: Origin of cross-chain geochemical variation in Quaternary lavas from the northern Izu arc: a quantitative mass-balance approach on source and mantle wedge process identification, Geochem. Geophys. Geosyst., 11, Q10011, doi:10.1029/2010GC003050, 2010.

Kincaid, C. and Sacks, I. S.: Thermal and dynamical evolution of the upper mantle in subduction zones, J. Geophys. Res., 102, 12295-12315, 1997.

Kirby, S. H., Engdahl, E. R., and Denlinger, R.: Intermediate-depth intraslab earthquakes and arc volcanism as physical expressions of crustal and uppermost mantle metamorphism in subduction slabs, in "Subduction: Top to Bottom", Geophysical Monograph Series, 96, edited by; G. Bebout, 195-214, American Geophysical Union, Washington, D.C., 1996.

Kneller, E. A. and van Keken, P. E.: Trench-parallel flow and seismic anisotropy in the Marianas and Andean subduction systems, Nature, 450, 1222-1225, 2007.

Kneller, E. A. and van Keken, P. E.: The effects of threedimensional slab geometry on deformation in the mantle wedge: implications for shear wave anisotropy, Geochem. Geophys. Geosyst., 9, Q01003, doi:10.1029/2007GC001677, 2008.

Lee, C. and King, S. D.: Effect of mantle compressibility on the thermal and flow structures of subduction zones, Geochem. Geophys. Geosyst., 10, Q01006, doi:10.1029/2008GC002151, 2009.

Lee, C. and King, S. D.: Why are high-Mg\# andesites widespread in the western Aleutians? A numerical model approach, Geology, 38, 583-586, 2010.

Long, M. D. and Silver, P. G.: The subduction zone flow field from seismic anisotropy: a global view, Science, 319, 315-318, 2008.

Long, M. D. and Becker T. W.: Mantle dynamics and anisotropy, Earth Planet. Sci. Lett., 297, 341-354, 2010.

Müller, R. D., Sdrolias, M., Gaina, C., and Roest, W. R.: Age, spreading rates, and spreading asymmetry of the world's ocean crust, Geochem. Geophys. Geosyst., 9, Q04006, doi:10.1029/2007GC001743, 2008.

Parai, R. and Mukhopadhyay, S.: How large is the subducted water flux? New constraints on mantle regassing rates, Earth Planet. Sci. Lett., 317, 396-406, 2012. 
Peacock, S. M. and Wang, K.: Seismic consequences of warm versus cool subduction metamorphism: examples from southwest and northeast Japan, Science, 286, 937-939, 1999.

Plank, T., Cooper, L. B., and Manning, C. E.: Emerging geothermometers for estimating slab surface temperatures, Nat. Geosci., 2, 611-615, 2009.

Skora, S. and Blundy, J.: High-pressure hydrous phase relations of radiolarian clay and implications for the involvement of subducted sediment in arc magmatism, J. Petrol., 51, 2211-2243.

Stadler, G., Gurnis, M., Burstedde, C., Wilcos, L. C., Alisic, L., and Ghattas, O.: The dynamics of plate tectonics and mantle flow: from local to global scales, Science, 329, 1033-1038, 2010.

Syracuse, E. M. and Abers, G. A.: Global compilation of variations in slab depth beneath arc volcanoes and implications, Geochem. Geophys. Geosyst., 7, Q05017, doi:10.1029/2005GC001045, 2006.

Syracuse, E. M., van Keken, P. E., and Abers, G. A.: The global range of subduction zone thermal models, Phys. Earth Planet. Int., 183, 73-90, 2010.

Toksöz, M., Minear, J., and Julian, B.: Temperature field and geophysical effects of a downgoing slab, J. Geophys. Res., 76, 11131138, 1971.

Tolstrup, D. L. and Gill, J. B.: Hafnium systematics of the Mariana arc: evidence for sediment melt and residual phases, Geology, 33, 737-740, 2005.

Turner, S., Caulfield, J., Turner, M., van Keken, P.E., Maury, R., Sandiford, M., and Prouteau, G.: Recent contributions of sediments and fluids to the mantle's volatile budget, Nat. Geosci., 5, 50-54, 2012.

van der Vorst, H. A.: Bi-CGSTAB: a fast and smoothly converging variant of Bi-CG for the solution of nonsymmetric linear systems, SIAM J. Sci. Comput., 13, 631-644, 1992.

van Hunen, J., van den Berg, A. P., and Vlaar, N. J.: On the role of subducting oceanic plateaus in the development of shallow flat subduction, Tectonophysics, 352, 317-333, 2002. van Keken, P. E., Kiefer, B., and Peacock, S. M.: High resolution models of subduction zones: implications for mineral dehydration reactions and the transport of water into the deep mantle, Geochem. Geophys. Geosyst., 3, 1056 , doi:10.1029/2001GC000256, 2001.

van Keken, P. E.: The structure and dynamics of the mantle wedge, Earth Planet. Sci. Lett., 215, 323-338, 2003.

van Keken, P. E., Currie, C., King, S. D., Behn, M. D., Cagnioncle, A., He, J., Katz, R. F., Lin, S. C., Parmentier E. M., Spiegelman, M., and Wang, K.: A community benchmark for subduction zone modeling, Phys. Earth Planet. Int., 171, 187-197, 2008.

van Keken, P. E., Hacker, B. R., Syracuse, E. M., and Abers, G. A.: Subduction factory 4: depth-dependent flux of $\mathrm{H}_{2} \mathrm{O}$ from slabs worldwide, J. Geophys. Res., 116, B01401, doi:10.1029/2010JB007922, 2011.

van Keken, P. E., Kita, S., and Nakajima, J.: Thermal structure and intermediate-depth seismicity in the Tohoku-Hokkaido subduction zones, Solid Earth, 3, 355-364, doi:10.5194/se-3-355-2012, 2012.

Wada, I. and Wang, K.: Common depth of slab-mantle decoupling: reconciling diversity and uniformity of subduction zones, Geochem. Geophys. Geosyst., 10, Q10009, doi:10.1029/2009GC002570, 2009.

Wada, I., Behn, M. D., and Shaw, A. M.: Effects of heterogeneous hydration in the incoming plate, slab rehydration, and mantle wedge hydration on slab-derived $\mathrm{H}_{2} \mathrm{O}$ flux in subduction zones, Earth Planet. Sci. Lett., 353-354, 2012.

Wiens, D. A., Conder, J. A., and Faul, U. H.: The seismic structure and dynamics of the mantle wedge, Annu. Rev. Earth Planet. Sci., 36, 421-455, 2008.

Zhong, S. J. and Gurnis, M.: Mantle convection with plates and mobile, faulted plate margins, Science, 267, 838-843, 1995. 